\title{
Novel Alkoxyaryl Substituted Porphyrins with Terminal Carboxymethyl and Carboxy Groups: Synthesis and Mesomorphic Properties
}

\author{
Kirill A. Formirovsky, ${ }^{\mathrm{a}}{ }^{1}$ Natal'ya A. Bragina, $^{\mathrm{a}}$ Andrey F. Mironov, ${ }^{\mathrm{a}}$ \\ Galina A. Ananieva, ${ }^{\text {b }}$ Venera V. Bykova, ${ }^{\text {b }}$ and Nadezhda V. Usol'tseva ${ }^{\mathrm{b} 2}$ \\ ${ }^{a}$ M.V. Lomonosov Moscow State Academy of Fine Chemical Technology, 119571 Moscow, Russia \\ ${ }^{\mathrm{b}}$ Nanomaterials Research Institute, Ivanovo State University, 153025 Ivanovo, Russia \\ ${ }^{\circledR 1}$ Corresponding author E-mail: former.ka@gmail.com \\ @2 Corresponding author_E-mail:nv_usoltseva@mail.ru
}

\begin{abstract}
The novel amphiphilic alkoxyaryl porphyrins bearing long chain substituents terminated with carboxy and carboxymethyl groups and their metal complexes have been synthesized. Their mesomorphic properties have been studied by optical polarizing microscopy.
\end{abstract}

Keywords: meso-Aryl substituted porphyrins, metallocomplexes, liquid crystals, mesophase.

Design of nanostructured materials based on amphiphilic porphyrins and their metal complexes is a new promising area. ${ }^{[1,2]}$ Porphyrins have all the necessary properties, including the availability of precursors, simplicity of synthesis and functionalization, thermal stability and specific photochemical properties, and the amphiphilic structure is crucial for self-assembly of supramolecular assemblies through noncovalent interactions. ${ }^{[1-3]}$ In this respect, liquid crystalline (LC) state is regarded as a way of achieving structural self-organization. ${ }^{[1]}$ Usually, to obtain the LC properties of tetrapyrrolic compounds the macrocycle is functionalized by long chain alkyl substituents, what also improves the solubility in nonpolar solvents and promotes surface immobilization. ${ }^{[4]}$ The introduction of metal usually leads to a change in mesomorphic properties. ${ }^{[4,5]}$ It is proved that the LC-based porphyrins are promising for optoelectronics, device display and storage. ${ }^{[6-8]}$

By now, a large number of mesogenic lipophilic porphyrins (both ligands and their metal complexes) with thermotropic and lyotropic mesomorphism have been described. ${ }^{[4-8]}$ It has also been reported that amphiphilic porphyrin derivatives containing sulfogroups possess lyotropic mesomorphism. ${ }^{[9,10]}$ We have demonstrated for cationic derivatives of 5,10,15,20-tetra-meso-aryl substituted porphyrins with terminal pyridinium groups that amphiphilic porphyrins possess thermotropic mesomorphism. At the same time a significant effect of the length of the aliphatic spacer and the metal nature on the liquid crystalline properties has been discovered. ${ }^{[11]}$

In this work we have synthesized the structural analogs of the above mentioned cationic porphyrins - amphiphilic tetraalkoxyaryl porphyrins (1-5) and studied their mesomorphic properties. These compounds have long chain substituents in which the spacer methylene chains with a length of five or ten carbon atoms separate the carboxy or carboxymethyl groups from the porphyrin macrocycle.

To obtain the 5,10,15,20-tetrasubstituted porphyrins $\mathbf{1}-\mathbf{3}$ we used an improved method of monopyrrole condensation in which the maximum yields of porphyrins were achieved at the concentrations of benzaldehyde and pyrrole equal to $10^{-2} \mathrm{M} \cdot{ }^{[12]}$ Based on the relevant substituted 4-hydroxybenzaldehyde and pyrrole according to the developed approach to the synthesis of lipophilic porphyrins ${ }^{[13]}$ we synthesized symmetrical meso-tetrakis(4-(methoxycarbonylalkyloxyphe

Table 1. The structures of the studied porphyrins $\mathbf{1}-\mathbf{5}$.

\begin{tabular}{cc} 
Structural formula & Substance \\
\hline
\end{tabular}


Table 2. Phase transition temperatures of compounds $\mathbf{1}-\mathbf{5}$.

\begin{tabular}{|c|c|c|c|}
\hline Substance & Phase transitions & $\begin{array}{c}\text { Lyotropic } \\
\text { mesomorphism* }\end{array}$ & $\begin{array}{c}\text { CT-complex } \\
\text { Thermotropics } \\
\text { mesomorphism* } \\
\end{array}$ \\
\hline 1 & $\begin{array}{c}\mathrm{Cr} \cdot 196.0^{\circ} \mathrm{C} \text { Iso } \\
\text { (Iso } \bullet 89.5^{\circ} \mathrm{C} \text { Mes } \bullet 71,8^{\circ} \mathrm{C} \text { was frozen with the texture of Iso) }\end{array}$ & - & \\
\hline 2 & $\mathrm{Cr} \bullet 204.0^{\circ} \mathrm{C}$ Iso & - & $+($ TAPA $)$ \\
\hline 3 & $\mathrm{Cr} \bullet 142.2^{\circ} \mathrm{C}$ Iso & + (chloroform) & $+($ TAPA $)$ \\
\hline 4 & $\begin{array}{c}\mathrm{Cr} \cdot 248.0^{\circ} \mathrm{C} \text { Iso } \\
\text { (Iso } \bullet 143.8^{\circ} \mathrm{C} \text { Mes } \bullet 72,4{ }^{\circ} \mathrm{C} \text { vitrified (glass) state with preserving } \\
\text { the mesophase texture at shift) }\end{array}$ & - & \\
\hline 5 & $\mathrm{Cr} \bullet 136.6^{\circ} \mathrm{C}$ Iso & - & $+(\mathrm{TNF})$ \\
\hline
\end{tabular}

* presence of mesomorphic properties.
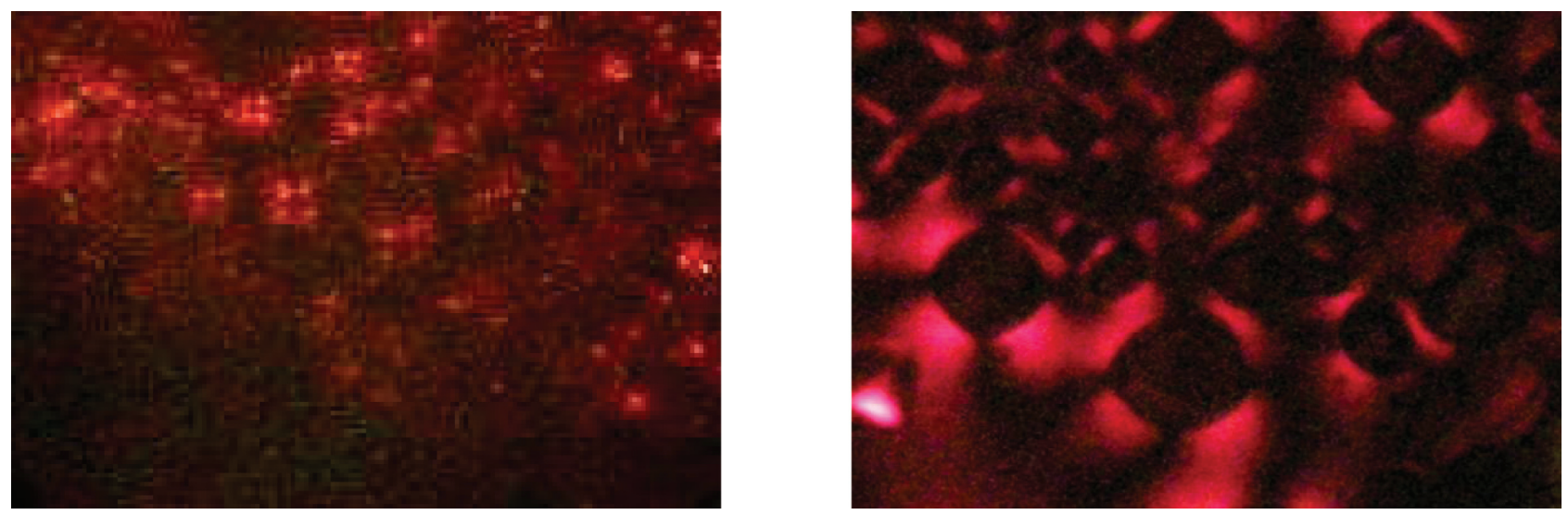

Figure 1. Microphotographs of the textures of thermotropic mesophases of compounds $\mathbf{1}$ and $\mathbf{4}$ with shear deformation, the cooling process, $87.7^{\circ} \mathrm{C}$ (for $\mathbf{1}$ ); shear strain, $72.4^{\circ} \mathrm{C}$ (for 4 ).

nylporphyrins)) 2 and 3 with $35-40 \%$ yields. Amphiphilic porphyrins with terminal carboxy groups were obtained with a quantitative yield by alkaline hydrolysis in a biphasic aqueous-organic system. On the basis of ligands 2 and $\mathbf{3}$ by standard techniques ${ }^{[14]}$ we prepared complexes with zinc, copper, cobalt and nickel with yields of $75-90 \%$. The structure of these compounds was confirmed by TLC, UVvis, ${ }^{1} \mathrm{H}-\mathrm{NMR}$ spectroscopy and liquid chromatography-mass spectrometry.

The resulting compounds are crystalline substances, very soluble in organic solvents. Porphyrins having carboxy groups dye aqueous alkaline solution.

The mesomorphic properties of compounds $\mathbf{1}-\mathbf{5}$ were studied by optical polarizing microscopy (Table 2). It was established that compounds $\mathbf{1}$ and $\mathbf{4}$ were mesomorphic on cooling in the temperature ranges $89.5-71.8^{\circ} \mathrm{C}$ and 143.8 $-72.4{ }^{\circ} \mathrm{C}$, respectively (Figure 1). The mesophases of these compounds are characterized by anon-geometric grain structure presumably associated with a column-type packing. [4] The study by contact preparation method of compounds 1 - 5 with toluene, benzene, chloroform, DMF, DMSO, cyclohexane, $\mathrm{H}_{2} \mathrm{O}$ and in aqueous ammonia solutions showed that only compound $\mathbf{3}$ possessed lyotropic mesomorphism in binary system with chloroform. Mesomorphic properties can be induced through the formation of charge transfer (CT) complex. ${ }^{[15]}$ This approach was used for the induction of mesomorphic state of nonmesogenic compounds $\mathbf{2 , 3}$ and $\mathbf{5}$.
Annealing of these compounds with 2,4,7-trinitrofluoren-9one(TNF) and 2-(2,4,5,7-tetranitro-9-fluorenilidenaminoxy) propionic acid ((-)-TAPA) yielded enantiotropic mesogenic zone of the CT-complex only in systems 2/TAPA, 3/TAPA and $\mathbf{5}$ /TNF.

In this work, we have synthesized and characterized the novel amphiphilic alkoxyaryl porphyrins having long chain substituents terminated with carboxy and carboxymethyl groups and their metal complexes. It was shown, that carboxylic compound with a chain length of 10 carbon atoms and carboxymethyl compound of zinc complex with the same chain length, possess thermotropic mesomorphism. Metal free carboxymethyl compound with a chain length of 10 carbon atoms possess lyotropic mesomorphism in binary system with chloroform. The mesomorphic state of nonmesogenic carboxymethyl compounds with chain lengths of 5 and 10 carbon atoms, as well as zinc complex with the chain length of 10 carbon atoms was induced by the CT-complex formation with TNF and TAPA.

As is well known from the literature, in corporation of coordinatively unsaturated metals $\left(\mathrm{Zn}^{\mathrm{II}}\right.$ and others) modifies considerably the properties of nonmesomorphic ligand..$^{[5,17]}$

Acknowledgments. This work was supported by RF Ministry for Education and Science (Analytical Departmental GoalOriented Program "Development of Scientific Potential of Higher Education” № 2.1.1./9396). 


\section{References}

1. Drain C.M., Varotto A, Radivojevic I. Chem. Rev. 2009, 109, 1630-1658.

2. Doan S.C., Shanmugham S., Aston D.E., McHale J.L. J. Am. Chem. Soc. 2005, 127, 5885.

3. Yamashita K., Akita Y., Asano M.S., Tanaka H., Kawai T., Sugiura K. J. Porphyrins Phthalocyanines 2010, 14, 10011058.

4. Usol'tseva N.V., Akopova O.B., Bykova V.V., Smirnova A.I., Pikin S.A. Liquid Crystals: Disk-like Mesogens (Usol'tseva N.V., Ed.), Ivanovo: Ivanovo State University. 2004, p. 128 (in Russ.).

5. Monobe H., Mima S., Sugini T., Shimizu Y. J. Mater. Chem. 2001, 11, 1383

6. Ichihara M., Miida M., Mohr B., Ohta K. J. Porphyrins Phthalocyanines 2006, 10, 1145.

7. Chou J.H. In: The Porphyrin Handbook (Kadish K.M., Smith K.M., Guilard R., Eds.), Vol. 6, Amsterdam: Academic Press, 2000, 346 p.

8. Eichhorn H. J. Porphyrins Phthalocyanines, 2000, 4, 88.
9. Usol'tseva N.V., Bykova V.V., Zharnikova N.V., Zharova M.A Mol. Cryst. Liq. Cryst. 2008, 494, 48.

10. Usol'tseva N.V. Lyotropic Liquid Crystals. Ivanovo: Ivanovo State University, 1994. p. 144 (in Russ.).

11. Aggarwal L.P.F., Borissevitch I.E. Spectrochim. Acta Part A 2006, 63, 227

12. Novikov N.V., Formirovsky K.A., Bragina N.A., Mironov A.F., Anan'eva G.A., Bykova V.V., Usol'tseva N.V. Mendeleev. Commun. 2010, 20, 239-242.

13. Lindsey J.S., Hsu H.C., Schreiman I.C. Tetrahedron Lett. 1986, $27,4969-4970$.

14. Fedulova I.N., Bragina N.A., Mironov A.F. Bioorg. Khim. 2007, 33, 635-639 (in Russ.) [Russ. J. Bioorg. Chem. 2007, 33, 589-593].

15. Porfiriny: Struktura, Svoistva, Sintez [Porphyrins: Structure, Properties, Synthesis] (Enikolopyan N.S., Ed.) Moskva: Nauka, 1987 (in Russ.)

16. Bengs H., Ebert M., Karthaus O., Kohne B., Praefcke K., Ringsdorf H., Wendorff J.H., Wuestefeld R. Adv. Mater. 1990, 2, 141-144.

17. Arunkumar C., Bhyrappa P., Varghese B. Tetrahedron Lett. 2006, 47, 8033-8037. 